\title{
Implementing Trauma Focused-Cognitive Behavioral Therapy for Youth under Probation: Lessons Learned
}

\author{
Maria Eva Pangilinan ${ }^{1 *}$ \\ ${ }^{1}$ County of Santa Clara Health System, California, USA \\ *Corresponding author: Maria Eva Pangilinan: eva_pangilinan@yahoo.com
}

\section{OPEN ACCESS \\ Citation: Pangilinan M.E. (2019) Implementing Trauma Focused- Cognitive Behavioral Therapy for Youth under Probation: Lessons Learned. Open Science Journal 4(1)}

Received: $13^{\text {th }}$ February 2019

Accepted: $29^{\text {th }}$ June 2019

Published: $30^{\text {th }}$ September 2019

Copyright: (C) 2019 This is an open access article under the terms of the Creative Commons Attribution License, which permits unrestricted use, distribution, and reproduction in any medium, provided the original author and source are credited.

Funding: The author(s) received no specific funding for this work

Competing Interests: The author has declared that no competing interest exists.

DOI:https://doi.org/10.23954/osj. v4i1.2012

\section{Abstract:}

OBJECTIVE: The implementation of Trauma Focused Cognitive Behavioral Therapy (TF-CBT) for youth under probation is underresearched. Since the TF-CBT project implementation goal was not met, the author aimed to address the following questions: What were the unaddressed barriers to TF-CBT participation and completion? What factors could have significantly impacted TF-CBT completion? Were the positive outcomes of TF-CBT on the project's proposed measures confirmed? The author also aimed to capture the lessons from the TF-CBT project implementation.

METHOD: Administrative documents were reviewed focusing on the project set-up, flow of participation and TF-CBT completion to identify the barriers. Chart reviews included data for 54 out of 60 TF-CBT participants. Three TF-CBT youth groups were identified. TF-CBT with no in vivo $(\mathrm{C} 7, \mathrm{n}=12)$, four to six TF-CBT components, including trauma narration $(\mathrm{C} 4-6, \mathrm{n}=$ $13)$, and one to four components in phase I of TF-CBT (C1-4, n $=29$ ). Groups were compared on demographics, pre-TF-CBT trauma and functioning, quality and fidelity of TF-CBT, justice involvement, and services satisfaction. Outcome measures were change scores on the UCLA Post Traumatic Stress Disorder Reaction Index, Youth Outcome Questionnaire and youth arrests. All statistical tests were set at $\mathrm{p}<.05$.

RESULTS: Of 154 youth referrals, 60 youth received at least one treatment session. 
Significant between-groups difference in parental involvement $\left(\chi^{2}=6.08, \mathrm{p}<.05\right)$ and number of trauma events experienced $(\mathrm{F}=3.58, \mathrm{p}<.05)$; and significant decrease in overall trauma symptom scores before and after TF-CBT participation with a very large effect size in group $\mathrm{C} 7(\mathrm{t}=3.73, \mathrm{p}<.001, \mathrm{~d}=1.08)$ were found.

LESSONS LEARNED: The barriers arising from the youth's distrust and therapist's skills were unaddressed. The therapists were possibly viewed by the youth as part of the police system (which justice involved youth likely do not trust). Future implementations must consider: the need for sufficient training of therapists; the value of clinical quality review, routine collection of information on families of justice involved youth, justifiable waiving of eligibility requirements; tracking on behaviors that are incompatible with those that warrant arrests; and, a coherent communications protocol.

Keywords: Juvenile justice, Youth under probation, Trauma, TF-CBT, Fidelity, PTSD

\section{Introduction}

Research and studies on crime and delinquency among youth documented as far back as the 1960s have shown that childhood trauma is a significant risk factor in juvenile delinquency and criminal behavior $[1,2,3,4,5,6,7,8,9]$. Symptoms of trauma have also been associated with delinquent or criminogenic behavior $[10,11,12,8]$. Persons with traumatic experiences relive disturbing memories, are chronically anxious, feel guilty, emotionally numb, and selfmedicate with drugs and alcohol [13, 14]. Untreated trauma negatively affects help-seeking and treatment engagement resulting in premature withdrawal from therapy and increasing the likelihood of committing another offense [15, 16, 17, 18, 19, 20, 21].

To date, Trauma-Focused Cognitive Behavioral Therapy (TF-CBT) has been shown by various studies to be more effective in helping children and families recover from trauma compared to other treatments typically used with traumatized children [22]. These studies include eight randomized controlled trials (RCTs) — including three with posttreatment follow-ups. In four other RCTs, TF-CBT was shown to be superior to waitlist conditions. In another RCT, TFCBT was found to be just as equally effective and efficient as eye movement desensitization and reprocessing (EMDR) therapy in improving PTSD symptoms. TF-CBT was superior for improving children's depressive and hyperactive symptoms than EMDR. In a fairly recent review and meta-analysis of studies on TF-CBT, the researchers had concluded that TF-CBT "is an effective 
intervention for the treatment of post-traumatic stress disorder (PTSD) in youth" [23].

TF-CBT consists of nine sequential components which may be completed in 8 to 12 weekly sessions: 1. Psychoeducation, 2. Relaxation skills, 3. Affective expression and modulation skills, 4. Cognitive coping and processing skills, 5 . Trauma narration and cognitive processing, 6. In vivo mastery of trauma reminders, 7. Conjoint child-parent sessions, and 8. Enhancing future safety and development. Parenting skills is a TF-CBT component that is provided along with each of these eight components. The acronym for these components is PRACTICE. TF-CBT requires gradual exposure to trauma reminders over three phases: I. stabilization and skills-building in the first four components, II. trauma narration and processing, and III. integration and consolidation in the last three components. All the components should be provided to all children receiving TFCBT treatment and therapists must have clear clinical justifications for changing the order of the PRACTICE components and/or exclusion of in vivo mastery. Provision of each component could take a full 90 min that is equally divided between the youth and the caregiver [24, 22].

In two independent RCTs, TF-CBT was demonstrated to be overall effective in trauma symptom reduction for youth in foster care (child welfare system) [25] and residential treatment facility (RTF) (juvenile justice systems) [26]. However, experts in mental health and juvenile justice have reported a lack of systematic research on TF-CBT for youth on probation [27, 28, 29]. Some of the reasons for this gap in research could be due to what Cohen et al. had pointed out [26]: in an RTF, the youth are more available to complete therapy and do not have to contend with the multitude of factors (that serve as barriers to completion) that could impede the therapy in outpatient settings; and the youth may also feel safer than in their own home or community environment.

A Bureau of Justice Assistance (BJA) Justice and Mental Health Collaborative Project (JMHCP) Grant proposed TF-CBT as an option for youth on probation in Santa Clara County (SC County) in California, with primary focus on nonviolent females. The data for the year prior to TF-CBT implementation showed that $46 \%$ of 3,555 youth ( $18 \%$ of which were females), under SC County court's jurisdiction were classified as nonviolent offenders. The TF-CBT Grant's goal was to have at least 60 youth complete TF-CBT each year during the duration of the Grant (i.e., at least a total of 120 youth in two years) [30]. However, in over three years of TF-CBT implementation, only 60 youth participated in the BJA funded TF-CBT and received at least one TF-CBT session [31]. Since the County's project implementation goal was not met and implementation of TF-CBT for youth under probation is underresearched, it is worthwhile to conduct this study to systematically explore answers to the following questions: What were the unaddressed barriers to TF-CBT participation and completion? What factors could have significantly impacted TF-CBT completion? Were the positive outcomes of TF-CBT on the project's proposed measures (i.e., trauma symptom reduction, improvement in the youth's mental and behavioral functioning and reduction in youth arrests) confirmed? What are the lessons learned from the TF-CBT project implementation? 


\section{Method}

A review of administrative documents was conducted to potentially identify the unaddressed barriers to participation. Client charts were reviewed to possibly identify the factors that significantly impacted TF-CBT participation and to reconfirm the positive outcomes of TF-CBT.

\section{Review of Administrative Documents}

The review of administrative documents was focused on the project set-up, flow of youth participation and completion of TF-CBT. Data reports on referrals and TF-CBT participation (i.e., data on the results of screening, admission, and completion); the 2011 project proposal; quarterly reports to BJA from the 4th quarter of 2011 through the second quarter of 2015; monthly management meeting minutes from 2012 to 2015, and; other reports from the TF-CBT lead clinic's lead therapist and the manager [30, 31] were reviewed.

\section{Charts Review: Factors that impact TF-CBT and reconfirm outcomes of TF-CBT}

Youth demographics, pre-TF-CBT trauma and functioning scores, justice system involvement, and services satisfaction, and; assessment and treatment services provided were analyzed for their impact on completion of TF-CBT. Consent to participate in the study was obtained and the sample of charts was limited to those who agreed to participate in the study. The University of California at Los Angeles (UCLA) Post Traumatic Stress Disorder for Children and Adolescents Reaction Index DSM-IV (Revision) scale (PTSD RI) [32], Youth Outcome Questionnaire (YOQ) [33], and youth arrests were used to assess TFCBT outcomes. The eight-item Consumer Satisfaction Questionnaire (CSQ-8) [34], was used to assess services satisfaction. Statistical analytic procedures were applied to compare three TF-CBT youth groups based on their demographic, clinical and justice-involvement characteristics.

Study participant's consent. TF-CBT therapists handed out and explained the Institutional Review Board (IRB) approved Study Participant's Consent Form to youth and parent as soon as appropriate during TF-CBT participation and informed youth and parent that study participation was voluntary. The consent form was available in two versions (youth only and parent/guardian only), and in three languages (English, Spanish, and Vietnamese) - this was considering that justice system involved youth in SC County who were 65\% Latinos/Hispanics, $15 \%$ Whites, 20\% Other Non-Whites were predominantly economically poor or very poor [30]; that the languages of the recipients of social services assistance (n $=236,070)$ included English (43\%), Spanish (37\%), Vietnamese (12\%), Chinese (4\%), Tagalog $(2 \%)$ or some other languages $(2 \%)$ in 2010 [35]; and advise by Mental Health Department (MHD) clinic staff for children and youth located at the Juvenile Probation Department (JPD).

Study sample. Data from March 2012 to March 2015 were reviewed for 54 of 60 youth who participated in TF-CBT. Excluded were four participants who did not sign the IRB approved consent forms and two who were still undergoing TF- 
CBT. Forms were signed in both versions for 44 youth, in youth only for six participants, in parent/guardian only for four participants.

Tools and measures. The BJA Grant proposed use of the following tools and measures: PTSD RI [32], YOQ [33], and youth arrests. The CSQ-8 [34] was selected to assess satisfaction with health services. The PTSD RI and YOQ were available in English and Spanish languages. These tools were translated with permission into Vietnamese using translating agencies assisted by MHD staff for back translations since Vietnamese was the third most prevalent language among CA State health insurance (MediCAL) beneficiaries in SC County [31], and it was also specifically requested by managers of mental health services to justice system involved youth. The CSQ was available in English, Spanish and Vietnamese languages.

(a) PTSD RI. The PTSD RI is not meant to be used as a diagnostic tool. The PTSD RI was used to screen for any trauma event, assess severity of reactions to the traumatic events (trauma symptoms), determine TF-CBT project eligibility based on 17 of the 22 PTSD RI items (PTSD RI-17), and assess the change in severity of reactions to trauma event(s) that were indicated before TF-CBT. Each item is rated on a scale from 0 to 4 (never to almost every day). The internal consistency or Cronbach's Alpha reliability $(\alpha)$ scores across versions of the PTSD $\mathrm{RI}$ were in the .90 s range and the test-retest reliability has ranged from good to excellent [36, 37]. While some filled out the forms independently, many youth or youth and parent were assisted by the TF-CBT therapists, taking 5 to 15 min to complete the forms. The therapists decided to administer the PTSD RI to the youth after completing TF-CBT.

In the current study, all 22 items of the PTSD RI [32] were remapped onto the new DSM-5 criteria for PTSD [38] which resulted in a 19-item scale (PTSD RI-19) but lacked an item for reckless or destructive behavior. The highest possible scores for PTSD RI-17 and PTSD RI-19 were 68 and 76, respectively.

(b) YOQ. The 30-item YOQ Version 30.2 [33] for either the adolescent or the parent was used to assess change in mental and behavioral functioning (Somatic, Social Isolation, Aggression, Conduct Problems, Hyperactivity/Distractibility, and Depression/Anxiety), with each of the items rated on a scale from 0 to 4 (never to almost always). The $\alpha$ score was .92 across versions and community sample and outpatient data. Only the total score was recommended in tracking treatment efficacy because the subscales needed further psychometric validation [39]. The YOQ was to be administered to eligible participants before and after they have completed TF-CBT.

In this study, to retain as many youth YOQ data as possible, a missing response to an item was replaced with the item sample mean for one youth. In another case, the YOQ subscales' scores with all items answered were included in the analysis but the total score was excluded. This was in accordance with the YOQ scoring procedure that invalidated a case if more than $10 \%$ of the 30 items were not answered [39].

(c) Youth Arrests. The youth arrests, types of arrests, and number of days in a locked Juvenile Probation Department facility (L-JPDf) were BJA's primary outcome measures. BJA required calendar year quarter (CY Qtr) reporting on the number of participants who were arrested, number of days in a L-JPDf, number of youth who completed or dropped out of the program. The SC County Juvenile Probation Department (JPD) uses the Juvenile Record System (JRS) and the 
Juvenile Arrest System (JAS) which are part of the Criminal Justice Information Center (CJIC) electronic data system. While JPD provided CY Qtr data extracts with dates unspecified, the JPD did not provide the arrests data prior to any of the youth's CY Qtr of TF-CBT participation. Because arrests were outcomes measures, the author confirmed that none of the youth was provided the final TF-CBT treatment (txFin) in a L-JPDf; none of the youth were in a L-JPDf for all 90 days of the last TF-CBT treatment CY Qtr; one was in a L-JPDf during the entire three CY Qtrs after the last TF-CBT treatment CY Qtr (i.e., post Qtr1, Qtr2, Qtr3), one during the entire post-TF-CBT CY Qtr1, and another during the full post-TF-CBT CY Qtr2.

(d) CSQ-8. The 8-item CSQ-8 was to be administered after the youth had completed TF-CBT. The response to the questions is a rating on a scale from 1 to 4 (poor to excellent). The overall score is the sum of all eight items. It has excellent psychometric properties [40,34].

Study design. The lead TF-CBT clinic's lead therapist identified the components covered per session for all study participants. This lead therapist (who was in direct communication with and received updates from TF-CBT therapists) reported on case status/issues at weekly clinical team meetings, and that the clinical team/therapists decided to not provide in vivo - the reasons cited were concerns with client safety associated with extended exposure to abusive home environments, dangerous (gangs) neighborhoods or difficulty in recreating the event.

Therapists reported a total of 23 participants as completed TF-CBT while 31 as not completed TF-CBT. However, chart reviews showed that four of those participants reported as completed TF-CBT actually completed only five components (ending TF-CBT with trauma narration and cognitive processing, component 5). Two of those reported as not completed TF-CBT, did complete five components. One reported as completed finished six components only - the reason was that the youth's parent could be incarcerated, hard to engage or dysfunctional families. Based on review of the number of TF-CBT components that were completed, missed, and sequence of completion, three distinct youth groups were identified. These groups are as follows:

One youth group was sequentially provided seven components or TF-CBT without in vivo mastery $(\mathrm{C} 7, \mathrm{n}=12)$. Therapists provided the conjoint childparent session (component 7) and enhancing future safety \& development (component 8) in one session for all youth in TF-CBT C7, and; one case had component 7 after component 8 .

A second youth group was nonsequentially provided four to six components, including the trauma narration and cognitive processing component $(\mathrm{C} 4-6, \mathrm{n}=$ 13). This group consisted of 11 youth who were reported by therapists as completed and two of the youth who were reported as not completed and had up to the trauma narrative and processing (component 5). In addition to missing in vivo, other components that were not provided to group C4-6 were: components 7 $\& 8(\mathrm{n}=6)$ for those ending with component 5 ; components $8(\mathrm{n}=3)$ or $3(\mathrm{n}=$ 1) for those ending with component 7 ; and components $1(\mathrm{n}=1)$ or $7(\mathrm{n}=2)$ for those ending with component 8 . In this group, the order of provision of the first four components were made to address the immediate needs of the youth (relaxation technique to address sleep problems prior to psychoeducation and parenting); prior components were reviewed before proceeding to the next to 
ensure that skills in the components were learned; two or more new components were introduced in one session in some cases, and then repeating components. Therapists started with components 2, 3, 4 or a combination for four youth; and component 4 before 3 for five youth. In a session, therapists provided a combination of the first four components for seven youth.

And a third group consisted of the youth who were provided one to four or any of the first four components of TF-CBT $(\mathrm{C} 1-4, \mathrm{n}=29)$. In a session, therapists provided a combination of the first four modules for two youth in TFCBT C1-4 and then reviewing the first four modules. Therapists started with components 2 or 3 for four youth; and component 4 before 3 for eight youth.

Statistical analysis. Descriptive data analysis and statistical tests were performed using SPSS v.22.0. All tests were set at $\mathrm{p}<.05$. Cohen's d was calculated for an estimate of effect size. Normality was set at 2.0 for skewness and kurtosis. The reliability of measurement tools were assessed. Nominal variables were coded and quantitative variables that violated the assumption of normality were recoded prior to statistical significance tests.

(a) Reliability of outcome and satisfaction tools. Cronbach's Alpha $(\alpha)$ tests were performed on the PTSD RI, YOQ and CSQ-8 to assess internal consistency of the scales. The PTSD RI-19 $\alpha$ scores before TF-CBT ranged from .80 to .89 for All participants, groups $\mathrm{C} 7$ and $\mathrm{C} 1-4$, and for groups $\mathrm{C} 7$ and $\mathrm{C} 4-6$ after TF-CBT. The PTSD RI-19 $\alpha$ scores for C4-6 were at .56 before TF-CBT and at .86 after TF-CBT. YOQ $\alpha$ scores were between .75 and .96 before and after TF-CBT for All participants and the three youth groups. Only the PTSD RI-19 and YOQ total scores were used for outcome analysis because of the overall low subscales reliability scores (see Appendix A for subscales $\alpha$ scores).

Table 1: Reliability of Pre and Post TF-CBT PTSD RI and YOQ Scales

\begin{tabular}{|c|c|c|c|c|c|c|c|c|}
\hline Scales & $\begin{array}{c}\text { All } \\
M(S D)\end{array}$ & $\alpha$ & $\begin{array}{c}\mathrm{C} 7 \\
M(S D) \text { range }\end{array}$ & $a$ & $\begin{array}{c}\mathrm{C} 4-6 \\
M(S D) \text { range }\end{array}$ & $a$ & $\begin{array}{c}\mathrm{C} 1-4 \\
M(S D) \text { range }\end{array}$ & $a$ \\
\hline & \multicolumn{8}{|c|}{ Pre-TF-CBT } \\
\hline Total PTSD RI-19 & $\begin{array}{c}n=51 \text { to } 54 \\
37.47(12.04)\end{array}$ & .80 & $\begin{array}{c}n=12 \\
41.42(12.63) 25-68\end{array}$ & .82 & $\begin{array}{c}n=11 \text { to } 13 \\
39.27(8.75) 22-54\end{array}$ & .56 & $\begin{array}{c}n=28 \text { to } 29 \\
35.07(12.89) 13-60\end{array}$ & .84 \\
\hline Overall YOQ & $\begin{array}{c}n=52 \text { to } 53 \\
46.70(16.93)\end{array}$ & .86 & $\begin{array}{c}n=12 \\
46.92(13.75) 20-71\end{array}$ & & $\begin{array}{c}n=13 \\
44.69(19.44) 21-88\end{array}$ & .91 & $\begin{array}{c}n=27 \text { to } 29 \\
47.59(17.47) 16-83\end{array}$ & .87 \\
\hline Total PTSD RI-19 & & & $\begin{array}{c}n=12 \\
23.75(12.50) 11-55\end{array}$ & $\begin{array}{l}\text { Post- } \\
.89\end{array}$ & $\begin{array}{l}-\mathrm{TF}-\mathrm{CBT} \\
n=10 \\
21.20(12.15) 0-37\end{array}$ & .86 & & \\
\hline Overall YOQ & & & $\begin{array}{c}n=8 \\
34.50(15.11) 12-55\end{array}$ & .86 & $\begin{array}{c}n=10 \\
26.90(22.89) 0-77\end{array}$ & .96 & & \\
\hline CSQ & $\begin{array}{c}n=21 \\
27.62(4.47)\end{array}$ & .92 & $\begin{array}{c}n=10 \\
26.40(5.78) 15-32\end{array}$ & .95 & $\begin{array}{c}n=11 \\
28.73(2.65) 25-32\end{array}$ & .82 & & \\
\hline
\end{tabular}

Note. TF-CBT $=$ Trauma-Focused Cognitive Behavioral Therapy; $\mathrm{C} 7=$ sequentially completed TFCBT without in vivo; C4-6 = nonsequentially completed 4 to 6 components including trauma narration \& processing; C1-4 = completed 1 to 4 of any one or a combination of the first four TF-CBT components; PTSD RI = Post Traumatic Stress Disorder Reaction Index; YOQ = Youth Outcomes Questionnaire; CSQ-8 = Client Satisfaction Questionnaire. 
The PTSD RI-17 $\alpha$ scores ranged from .75 to .88 for All participants, for C7 and C1-4 before TF-CBT, and for C7 and C4-6 after TF-CBT. The PTSD RI-17 $\alpha$ scores for C4-6 before and after TF-CBT were .32 and .85 , respectively. The pre-TF-CBT $\alpha$ scores for the full scale, and the subscales reexperiencing (5 items), avoidance (7 items), and increased arousal (5 items) subscales were .75, $.73, .53$ and .47 , respectively. The post-TF-CBT a scores were $.88(\mathrm{n}=12)$ for $\mathrm{C} 7$ and $.85(\mathrm{n}=10)$ for $\mathrm{C} 4-6$. The post-TF-CBT CSQ $\alpha$ scores were in the .90s range for All participants and $\mathrm{C} 7$, and .82 for C4-6.

(b) Statistical tests. Chi-squared $\left(\chi^{2}\right)$ and F-tests were performed to assess for the impact of youth demographic and clinical characteristics, youth justice system involvement, and measures of quality and fidelity of TF-CBT on completion of TF-CBT. Chi-squared tests were performed to assess for significant difference between TF-CBT services groups (BGs) on the following categorical or binomial coded variables: sex, ethnicity, preferred language, number of symptom domains met on the PTSD RI-17, arrests during TF-CBT, types of arrests, number of days in a L-JPDf, number of days between the last ATCP and tx1, number of in-person ATCP sessions, parental involvement, number of components completed, and duration of engagement in CY Qtrs. F-tests were conducted to assess for significant difference BGs on the following continuous variables: age, pre-TF-CBT number of trauma events experienced, pre trauma score on PTSD RI-19, pre YOQ score, end and start time lags, number of treatment sessions (txS), total amount of time for services received in min, number of days engaged from the youth's TF-CBT tx1 to txFin, and average number of days between txS. Significant BGs difference tests were not performed on the amount of time spent per session because of the high kurtosis found for this variable. F-test was performed to assess for significant difference in services satisfaction between $\mathrm{C} 7$ and C4-6.

To reconfirm the positive outcome of TF-CBT, the youth's pre and post TFCBT PTSD RI and YOQ data were analyzed. Paired samples t-tests were performed to assess change before and after TF-CBT participation in symptom reduction on the PTSD RI, and improvement in mental and behavioral functioning on the YOQ. The trauma symptom reduction outcome of TF-CBT could only be performed for C7. Assessing trauma symptom reduction for C4-6 was not performed due to the low internal consistency of the PTSD RI-19 scores before TF-CBT $(\alpha=.56)$ (see Table 1$)$. Since the PTSD RI and YOQ were intended to be administered after completing TF-CBT, data were not found for the C1-4 youth who were reported by therapists as not completed TF-CBT. Paired samples t-tests were performed (a) for C7 and C4-6 to assess improvement in mental and behavioral functioning on the YOQ before and after TF-CBT participation. The youth's post-TF-CBT justice involvement data were examined. Chi-squared tests were performed at each of the post TF-CBT CY Qtr of participation to assess significant difference BGs in justice system involvement (arrests during TF-CBT, time spent in a L-JPDf, and the type of arrests).

(c) Coding of factors. The five parental (parent/s, family member $/ \mathrm{s}$ or guardian) involvement categories were (i) therapist played the parent role, (ii) parent was involved during assessment only, (iii) parent was inconsistently involved, (iv) family member was involved, and (v) parent was involved. These five categories were regrouped into three and two categories (respectively, categories i plus ii, iv plus v, and iii; AND categories i plus ii plus iii, and iv plus 
v). The categories for the types of arrests were (i) none, (ii) administrative violation for the same offense, (iii) a new offense, and (iv) administrative violation for the same offense plus new offense. Arrests during TF-CBT was the sum of all arrests coded as 1 (arrests) or 0 (no arrest) in each CY Qtr of TF-CBT participation, since arrests could occur: before or after ATCP, before tx1 in the first CY Qtr of TF-CBT participation, or after the last TF-CBT treatment in the last CY Qtr of TF-CBT participation. Time spent in a L-JPDf during TF-CBT was the sum of the actual number of days in L-JPDf for all the CY Qtrs during TF-CBT coded as 1 (not a day) or 0 (a day or more) because the dates were unspecified. Number of days for ATCP was coded 1 (no more than two sessions) or 0 (more than two sessions) since per therapists, it had generally taken them one to two sessions for ATCP even with youth groups referred by social services agencies. Number of days between the last ATCP and tx1 was coded as 1 (no more than seven days) or 0 (more than seven days) to be in alignment with the TF-CBT recommended weekly face-to-face sessions and limits the duration of exposure by the youth to other events that might significantly bear on the preTF-CBT scores on the PTSD RI and YOQ.

Additionally, the start time lag and the end time lag were assessed for any significant BGs difference, given that those who start TF-CBT later in the first treatment CY Qtr or end earlier in the last treatment CY Qtr may have arrests and the time/days spent in a L-JPDf prior to starting or after ending TF-CBT. Within the treatment CY Qtr, the start time lag was the difference between the date of tx1 and the first day of the treatment CY Qtr. The end time lag was difference between the date of the last TF-CBT treatment and the last day of the treatment CY Qtr.

\section{Results}

The SC County Superior Court formed a TF-CBT project collaborative planning and implementation $(\mathrm{P} \& \mathrm{I})$ committee for the SC County Superior Court, JPD, and MHD to prepare for project implementation. The P\&I committee provided oversight to development of the BJA approved project implementation plan (including staffing and funding) and during implementation. The data revealed that: $31.82 \%$ of the youth referred by JPD to MHD did not respond, $12.7 \%$ of eligible youth declined participation, $47.89 \%$ of the trauma assessed youth were returned by MHD to JPD due to ineligibility, and $57.41 \%$ of study participants were reported as not completing TF-CBT. No significant findings were found based on youth demographic characteristics, justice involvement and services satisfaction. Significant findings suggested that completion of TF-CBT was associated with parental involvement during TF-CBT sessions, the number of trauma events experienced by the youth before TF-CBT, and some of the measures of the quality and fidelity of TF-CBT for the youth. Trauma symptom reduction outcome of TF-CBT (on the PTSDI RI-19) was confirmed only in $\mathrm{C}$, which was the least traumatized and most engaged of the three TF-CBT services youth groups. 


\section{Project Set-Up: Prior to implementing TF-CBT}

The P\&I committee had ensured readiness for implementation with a trained clinical team, a referral and recruitment system between JPD and MHD, an admission criteria, data collection system, and client consent forms [31]. Approval by the SC County's Institutional Review Board (IRB) for outpatient services of a proposed study on the effectiveness of TF-CBT for youth under probation was secured.

Clinical team. The project started with one clinic and two therapists already trained in TF-CBT. TF-CBT therapists licensed as clinical social workers (LCSW) or marriage and family therapists (LMFT) received eight hours of online trainings that covered each of the TF-CBT components and a two-day intensive training (14 hours) on each of the components. These therapists with at least 10 years of clinical work experience had been trained in cultural-competence by MHD and prior to working with MHD. Weekly consultations with the MHD manager with extensive TF-CBT work experience was available.

Recruitment and referral. All youth under a general court order to seek and undergo counseling and referred by the JPD to the MHD for assessment between February 2012 and February 2015 were contacted by telephone by a TF-CBT therapist. Probation Officers (POs) were trained to introduce TF-CBT as one of the options that potential TF-CBT project participants could select. To recruit youth on probation, POs and the TF-CBT clinical team jointly presented to youth at JPD their available counseling options, including TF-CBT. POs alerted MHD staff of any referrals and the date of youth's appearance before the Judge in the Juvenile Court. MHD clinicians returned completed Status Report Forms to JPD/POs [31].

Admission criteria. TF-CBT was offered to youth under the jurisdiction of SC Juvenile Court who met the following criteria: (i) the youth was legally nonviolent (ii) the youth's trauma experience was confirmed by a TF-CBT therapist by the PTSD RI [32] (iii) the State of CA and MHD medical necessity requirements were met (iv) the eligibility cutoff score on the PTSD RI was met, and (v) the assigned therapist determined that TF-CBT was the appropriate first-line treatment.

Data collection. The BJA Grant required aggregate CY quarterly reports on data relevant to the objectives of the project. These were the number of participants who completed and did not complete TF-CBT, number of participants arrested, number of participants arrested for administrative violation for the same offense or a new offense, total number of days spent in a L-JPDf by participants, and number of participants hospitalized for mental health-related illness during CY Qtr reporting timeframes. The latter was not collected since the project was not set up for that. MHD set up its EHR for fiscal management and evaluation data collection, including demographics and services data, and had provided oversight for clinical consultations. MHD wad poised to submit required CY Qtr arrests data reports out of CJIC to BJA on the participants who were arrested, the types of arrests and the number of days in a L-JPDf, and program completion reports based on therapists manual tracking of program completion (i.e., TF-CBT completion for this project). Monthly reports were provided by MHD to the P\&I committee on the number of youth who were referred by JPD, screened and admitted by MHD, and dropped out of TF-CBT. Additionally, as 
proposed in the BJA Grant, a focus group discussion (FGD) was conducted midyear into TF-CBT implementation. It explored what worked and what did not work with active TF-CBT youth and parent participants.

\section{Project Set-Up: During implementation of TF-CBT}

The P\&I committee met every month at the Juvenile Court Judge's Chamber, accessed technical assistance and submitted quarterly reports to BJA. This monthly meetings facilitated discussions to making adjustments to referrals and admission criteria (as soon as MHD reported low referrals from JPD and nonresponse by the youth), and redefining the nonviolent criteria. The P\&I committee was updated on MHD discussions on having more clinics and therapists available for TF-CBT to improve access to TF-CBT, and adding motivational interviewing during assessment — therapists have reported about needing more time during assessment and treatment planning, about difficulty in connecting with the youth or establishing alliance, and that assessment and treatment care planning had taken longer because of youth's low trust. Managers supported letting therapists decide on when therapy was considered completed and reporting completion.

Adjustments to admission criteria. TF-CBT was offered to youth under the jurisdiction of SC Juvenile Court. The cutoff score on the PTSD RI was lowered from: 30 to 25 within three months of project implementation; 25 to 20 around the third quarter of implementation; and after a year into the project, further relaxed to meeting at least one of three symptom-domain criterion: reexperiencing, avoidance and increased arousal on the PTSD RI [31]. Furthermore, of the 54 youth participants in this study, 15 met one trauma symptom-domain, 23 met two symptom-domains, and 14 met 3 symptomdomains (respective range of scores: 13-37, 21-41, and 34-62). One youth participant had a pre-post TF-CBT YOQ, and a post-TF-CBT but not pre-TFCBT PTSD RI data; and another youth participant, who was exposed to traumatic events did not meet any symptom domain criteria scored 13 .

Redefining the legal definition of nonviolent youth. Originally, the TF-CBT Grant was intended for nonviolent youth (prioritizing females) with no history of violence. However, due to insufficient count and low response from the youth referred by JPD, the nonviolent criterion was redefined (within the first Qtr of implementation) to mean the youth's current arrest was not for violence and still met the funding's requirement of legally nonviolent youth (defined by the State of CA Code).

A year and a half into the TF-CBT project - considering the insufficient number of female youth with no history of violence, JPD also referred to MHD those whose arrests at the time of referral were for nonviolence; females on judicial deferment pending probation period; and, 11 to 14 -year-old males [31].

Improvements to access clinical services. Midyear into the first year of project implementation, adjustments were made following the findings and suggestions from the FGD. The implementation was expanded to four county clinics with 13 therapists trained in TF-CBT to address and avoid service access issues (e.g., wait time, clinic location, and staffing). All therapists had cultural competence trainings. Three bilingual (English-Spanish) and bicultural (Latinos/Hispanics) therapists were available. Participants were matched as closely as possible, with 
linguistically or culturally appropriate clinicians. For the convenience of youth and their families, and with due consideration for safety of therapists, TF-CBT sessions were held in schools, homes, L-JPDf, or SC County outpatient clinics [31].

Incorporating motivational interviewing. Motivational interviewing was added to the clinical assessment before the end of the first year of implementation to improve youth engagement (anticipate barriers to engagement and to avoid premature disengagement/terminations). By the second year of TF-CBT implementation, therapists who had the option to seek guidance, consulted with Dr. Anthony Mannarino (one of the TF-CBT developers).

Reporting of completion. Clinic managers also approved/supported reporting completion per therapist's judgment by the end of the first year of implementation. In over three years, only 23 of 54 participants were reported by therapists as completed TF-CBT and 31 were reported as dropped out or did not complete TF-CBT.

\section{Flow of Youth Participation and TF-CBT Completion}

Of 154 youth referred by JPD to MHD (whose arrests at the time of referral were confirmed as not for violent behaviors), 105 were screened and assessed, while 49 did not respond or declined assessment. Of these 105 who were screened and assessed between March 2012 and March 2015 by MHD: 71 were eligible and offered TF-CBT, and 34 were not offered TF-CBT (30 did not meet any of the prior eligibility criteria or any one of three symptom-domain criterion on the PTSD RI to be eligible; and, four referred in the beginning of the program were disqualified based on two prior eligibility cutoff scores on the program eligibility tool). The 34 who were disqualified were referred back by MHD to JPD. Of those 71 eligible youth (a) 60 received at least one individual TF-CBT treatment session including one who was transferred to a community-based provider because a TF-CBT was established locally (b) two started TF-CBT in April 2015 and were no longer tracked for this study, and (c) of the nine remaining eligible youth, two declined participation while seven did not show up for any session due to among others relocation or pregnancy - the reasons for declining were: therapy was not needed, and nonacceptance of screening results. Of the 54 youth participants, four withdrew after the first session, seven after the third and three after the fourth. One participant completed TF-CBT in seven sessions, and the rest $(\mathrm{n}=39)$ finished at least eight sessions (including 15 who had one or more of the first four TF-CBT components).

Per the anecdotal reports of therapists of youth nonresponse, nonresponse could be due to changes of POs (who are routinely reassigned elsewhere) that may have affected continuity of communications with the youth. Reassignment of POs may have disrupted establishing connection and in turn lead to nonresponse or low response. JPD/POs and MHD/therapists have stated that poor response could be due to dysfunctional families and their unaddressed needs (associated with a parent's incarceration, health or economic issues). Regarding the premature therapy withdrawal, therapists offered these reasons (a) the unaddressed youth's dysfunctional families' needs and that youth whose parents were not involved tended to drop out (b) youth's loss of interest after getting off probation, getting rearrested or absconding, scheduling conflicts with other court- 
required programs, and (c) TF-CBT did not adequately address the needs associated with symptoms of comorbidities manifested during TF-CBT.

\section{Impact of Characteristics of TF-CBT Youth Groups and TF-CBT Completion}

Demographics and justice involvement did not significantly impact TF-CBT completion. Majority of All youth participants were Latinos/Hispanics (68.5\%), were males (57.4\%), and indicated English as their preferred language $(92.6 \%)$. On average, the youth were 16 years old; and, had an average start lag of 41 days (range, 6 to 85) and end lag of 51 days (range, 9 to 90). The sum of arrests during TF-CBT averaged one (range, 0 to 3). The average number of days in a L-JPDf was 23 (range, 0 to 161). The current study found no significant difference BGs in demographic composition and in juvenile justice system involvement during TF-CBT (see Table 2).

Table 2: Youth Demographic Characteristics and Justice System Involvement

\begin{tabular}{|c|c|c|c|c|}
\hline & $\begin{array}{c}\text { All } \\
n=54\end{array}$ & $\begin{array}{c}\text { C7 } \\
n=12\end{array}$ & $\begin{array}{c}\text { C4-6 } \\
n=13\end{array}$ & $\begin{array}{c}\mathrm{C} 1-4 \\
n=29\end{array}$ \\
\hline \multicolumn{5}{|l|}{ Youth Demographic Characteristics } \\
\hline Sex: Male & $(57.4 \%)$ & $7 \quad(58.3 \%)$ & $8(61.5 \%)$ & $16(55.2 \%)$ \\
\hline Female & $(42.6 \%)$ & $5 \quad(41.7 \%)$ & $5(38.5 \%)$ & $13(44.8 \%)$ \\
\hline Ethnicity: Latino/Hispanic & $(68.5 \%)$ & $8 \quad(66.7 \%)$ & $8(61.5 \%)$ & $21 \quad(72.4 \%)$ \\
\hline White & $(13.0 \%)$ & $2(16.7 \%)$ & $1 \quad(7.7 \%)$ & $4 \quad(13.8 \%)$ \\
\hline Black & $(5.6 \%)$ & $1 \quad(8.3 \%)$ & $0 \quad(0.0 \%)$ & $2(6.9 \%)$ \\
\hline Asian, PI, \& Native American ${ }^{a}$ & $(7.6 \%)$ & $(0.0 \%)$ & $3(23.1 \%)$ & $1 \quad(3.4 \%)$ \\
\hline Other/Unknown & $(5.6 \%)$ & $(8.3 \%)$ & $(7.7 \%)$ & $(3.4 \%)$ \\
\hline Preferred Language: English & $(92.6 \%)$ & $11(91.7 \%)$ & $11(84.6 \%)$ & $28 \quad(96.6 \%)$ \\
\hline Spanish & $(5.6 \%)$ & $(9.1 \%)$ & $1 \quad(7.7 \%)$ & $1 \quad(3.4 \%)$ \\
\hline \multirow[t]{2}{*}{ Vietnamese } & $(1.9 \%)$ & $(0.0 \%)$ & $(7.7 \%)$ & $(0.0 \%)$ \\
\hline & \multicolumn{4}{|c|}{$M(S D)$ range } \\
\hline Age at assessment (in years) & $16.2(1.1)$ & $15.9(1.1) 14-17$ & $16.2(0.9) 14-17$ & $16.3(1.2) 14-18$ \\
\hline \multicolumn{5}{|l|}{ Justice System Involvement during TF-CBT } \\
\hline TF-CBT start lag (in days) & $41.3(22.5)$ & $42.6(19.8) 9-77$ & $43.1(24.3) 7-78$ & $40.0(23.3) 6-85$ \\
\hline TF-CBT end lag (in days) & $50.6(25.1)$ & $43.5(24.8) 10-91$ & $53.0(27.0) 9-87$ & $52.5(24.6) 9-90$ \\
\hline Sum of Qtr arrests (coded 1 or 0 per Qtr) & $0.8(1.0)$ & $1.0(1.2) 0-3$ & $0.5(0.9) 0-3$ & $0.8(1.0) 0-3$ \\
\hline Days in locked juvenile facility & $22.7(40.0)$ & $28.7(44.7) 0-114$ & $18.5(44.1) 0-154$ & $22.1(37.3) 0-161$ \\
\hline
\end{tabular}

Note. TF-CBT = Trauma-Focused Cognitive Behavioral Therapy; C7 = sequentially completed TF-CBT without in vivo; C4-6 = nonsequentially completed TF-CBT, including trauma narration \& processing; C1-4= completed 1 to 4 of any one or a combination of the first four TF-CBT components; PI = Pacific Islander; Qtr = quarter. a Combined to avoid identification.

Clinical characteristics of youth groups had impact on TF-CBT completion. More than half of the youth participants $(64.8 \%, \mathrm{n}=54)$ had a parent or family member involved consistently during treatment sessions. The number of sessions for the therapists to complete in-person ATCP prior to TFCBT tx1 ranged from 1 to 8 , and $61.1 \%$ of the participants took three or more in-person sessions. The number of trauma events experienced by the youth before TF-CBT ranged from 1 to 13 and averaged five. The number of TF-CBT 
txS ranged from 1 to 24 and the average was nine. Instead of strict weekly sessions, the average number of days between TF-CBT txS became 16 days because the youth cancelled or did not show up as scheduled (see Table 3 ).

Table 3: Clinical Characteristics by TF-CBT Services Group

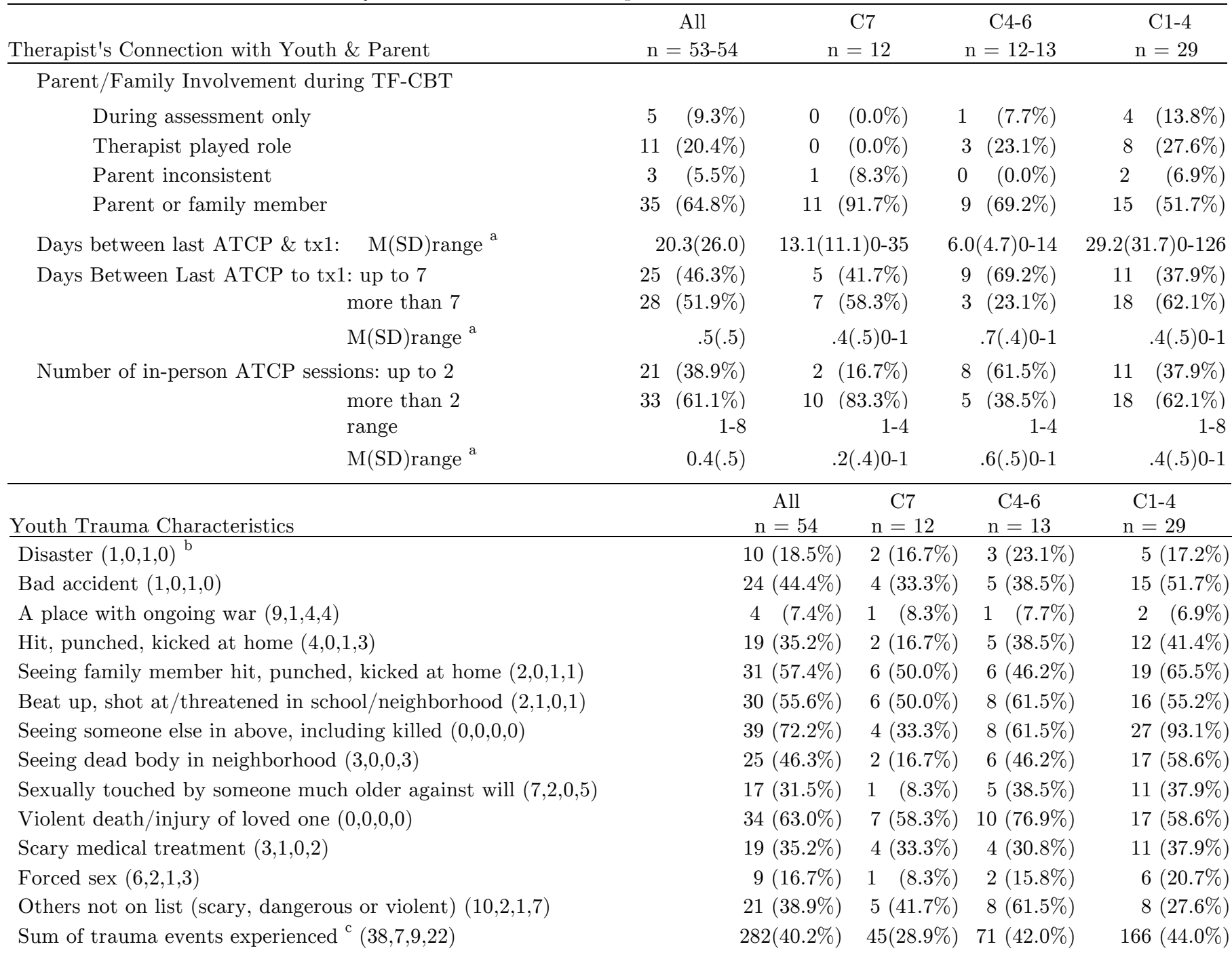

\begin{tabular}{|c|c|c|c|c|}
\hline \multirow[b]{2}{*}{ Number of PTSD symptom domains } & \multicolumn{4}{|c|}{$\mathrm{M}(\mathrm{SD})$ range } \\
\hline & $1.9(1.0)$ & $2.2(0.6) 1-3$ & $1.8(0.8) 1-3$ & $1.9(0.8) 0-3$ \\
\hline Number of trauma events experienced & $5.3(2.4)$ & $3.8(1.5) 1-6$ & $5.7(2.3) 2-11$ & $5.7(2.5) 2-13$ \\
\hline Quality and Fidelity of TF-CBT & \multicolumn{4}{|c|}{$\mathrm{M}(\mathrm{SD})$ range } \\
\hline Engagement duration (in CY Qtr) & $2.5(1.0)$ & $3.2(.6) 2-4$ & $2.8(.8) 1-4$ & $2.0(.9) 1-4$ \\
\hline Number of days engaged in program & $132(80)$ & 201(38.7)133-259 & $156(63) 74-302$ & $93(76) 0-252$ \\
\hline Number of components completed & $4.2(2.1)$ & $7.0(0) 7-7$ & $5.5(0.8) 4-6$ & $2.5(1.0) 1-4$ \\
\hline Number of TF-CBT txS & $9.0(5.5)$ & $13.6(5.0) 7-22$ & $12.3(4.5) 8-24$ & $5.6(3.6) 1-15$ \\
\hline Average of number of days between txS ${ }^{\mathrm{d}}$ & $16.1(8.7)$ & $17.0(8.0) 7.8-37.0$ & $13.5(6.6) 8.2-33.6$ & $17.1(10.0) 4.8-41.7$ \\
\hline Average of time spent per txS (in min) & $76.8(17.9)$ & $71.2(8.8) 53-83$ & $76.2(12.0) 63-111$ & $79.5(17.9) 30-143$ \\
\hline Services received (in min) & $675(425)$ & $963(346) 459-1605$ & $940(361) 503-1695$ & $437(336) 45-1734$ \\
\hline
\end{tabular}

Note. TF-CBT = Trauma-Focused Cognitive Behavioral Therapy; C7 = sequentially completed TF-CBT without in vivo; C4-6 = nonsequentially completed TF-CBT 4 to 6 components, including trauma narration \& processing; C1-4= completed 1 to 4 of any one or a combination of the first four TF-CBT components; ATCP = assessment and treatment care planning; tx1 = first TF-CBT 
treatment session; PTSD = post-traumatic stress disorder; txS $=$ TF-CBT treatment session(s). CY Qtr $=$ calendar year quarter(s). ${ }^{\mathrm{a}}$ values indicated are $M(S D)$ range. ${ }^{\mathrm{b}}$ Number of missing responses on 12 events for columns left to right. ${ }^{\mathrm{c}}$ Denominator $=$ sample size $n \times 13$ events. ${ }^{\mathrm{d}} n=50$ for All and $n=25$ for C1-4.

(a) Parental involvement impacted completion. Significant difference BGs was found in parental involvement during TF-CBT sessions (two categories: $\chi^{2}$ $=6.08, \mathrm{df}=2, \mathrm{p}=.048 ;$ three categories: $\mathrm{LR}=12.04, \mathrm{df}=4, \mathrm{p}=.017)$. Almost all of the youth in $\mathrm{C} 7 \mathrm{had}$ parents consistently involved during TF-CBT $(91.7 \%)$ compared to C4-6 (69.2\%) and C1-4 (51.7\%) (refer to Table 3). No significant difference BGs was found in the time interval between the last ATCP and tx1 and number of in-person ATCP sessions.

(b) Youth trauma events experienced impacted completion. For All youth participants $(\mathrm{n}=54)$ the average number of trauma symptom-domains indicated before TF-CBT by the youth was two (see Table 3), symptom scores on the PTSD RI-19 was 37.47 (range, 22 to 60); and the mental and behavioral functioning scores on the YOQ was 46.70 (range, 16 to 88) (see Table 1). C7 was the least traumatized (28.9\% of the group had exposure to 1 to 6 traumatic events) compared to C4-6 (42\% had experienced 2 to 11 traumatic events) and the youth in $\mathrm{C} 1-4$ ( $44 \%$ had 2 to 13 traumatic events experienced). C1-4 was relatively more traumatized than $\mathrm{C} 4-6$ and $\mathrm{C} 7$ (more than $50 \%$ of the youth in C1-4 indicated having experienced 6 of 12 , average $=6$ events) compared to 3 of 12 events (average $=6$ ) in C4-6, and 1 of 12 events (average $=4$ ) in C7 (see Table 3). Significant BGs difference was found in number of trauma events experienced $(\mathrm{F}=3.58 \mathrm{df}=2, \mathrm{p}=.035)$. No significant difference BGs was found in number of symptom domains and total scores on trauma symptoms and functioning.

(c) Quality and fidelity of TF-CBT. For All participants, the total amount of time for services received ranged from 45 to $1734 \mathrm{~min}$ (average, $675 \mathrm{~min}$ ), the average number components completed was five and amount of time spent per session was 76.8 minutes (range, 53 to $143 \mathrm{~min}$ ) (see Table 3). The groups significantly differed (a) in total number of days engaged in the program ( $\mathrm{F}=$ 12.44, $\mathrm{df}=2, \mathrm{p}=.000)$ and duration of engagement in $\mathrm{CY} \mathrm{Qtr}\left(\mathrm{\chi}^{2}=16.70, \mathrm{df}=\right.$ $6, \mathrm{p}=.010)$, and (b) in quality based on number of txS $(\mathrm{F}=21.44, \mathrm{df}=2, \mathrm{p}=$ $.000)$, total amount of time for services received $(\mathrm{F}=15.00, \mathrm{df}=2, \mathrm{p}=.000)$, and the number of components provided $\left(\chi^{2}=94.86, \mathrm{df}=12, \mathrm{p}=.000\right)$. No BGs difference was found in the average number of days between TF-CBT txS and in all the other measures of quality and fidelity of TF-CBT that were examined. Of the three groups, C7 had the most number of sessions, amount of time received, and longest duration of engagement (in addition to $\mathrm{C} 7$ having the most number of components completed) while C1-4 had the least in fidelity of TF-CBT.

Also noted: Trauma narration and processing was provided more than four times to youth in $\mathrm{C} 7(\mathrm{n}=5$, with one who had an 8- and then 38-min sessions on the same day) and $\mathrm{C} 4-6(\mathrm{n}=7$, with one who had a 23 - and then 70 -min sessions on the same day). TF-CBT components provided in at least three different sessions were: (a) trauma narration and processing to youth in $\mathrm{C} 7(\mathrm{n}=8)$, and C4-6 ( $\mathrm{n}=11)$; (b) cognitive coping and processing to youth in $\mathrm{C} 7(\mathrm{n}=2)$, $\mathrm{C} 4-6$ $(\mathrm{n}=1)$ and $\mathrm{C} 1-4(\mathrm{n}=2) ;(\mathrm{c})$ affect expression and modulation to youth in $\mathrm{C} 7(\mathrm{n}$ $=1)$, C4-6 $(\mathrm{n}=1)$, and C1-4 $(\mathrm{n}=2) ;(\mathrm{d})$ relaxation to youth in C1-4 $(\mathrm{n}=4)$; 
and (e) psychoeducation and parenting to youth in C4-6 $(\mathrm{n}=1)$ and C1-4 $(\mathrm{n}=$ 1). $24.1 \%$ completed all four components in phase $\mathrm{I}$ in 8 to 15 sessions.

\section{Satisfaction with Services Had No Impact on TF-CBT Completion}

There were a few indicated that the program did not meet or met only very little of their needs $(\mathrm{n}=3)$, the amount of help was not satisfactory $(\mathrm{n}=2)$, or they would not come back $(\mathrm{n}=3)$. The program satisfaction average score was high at 3.3 (TF-CBT C7, $\mathrm{n}=10$ ) and $3.6(\mathrm{TF}-\mathrm{CBT} \mathrm{C} 4-6, \mathrm{n}=11$ ) on a scale of 1 to 4. Groups $\mathrm{C} 7$ and $\mathrm{C} 4-6$ were not significantly different in services satisfaction on CSQ-8 total sum of scores.

\section{Significant Trauma Symptom Reduction Was Found in $C 7$ (TF-CBT without in vivo)}

This study found significant decrease in overall trauma symptom scores on the PTSD RI-19 before and after TF-CBT participation with a very large effect size in group $\mathrm{C} 7(\mathrm{t}=3.73, \mathrm{p}<.001, \mathrm{n}=12, \mathrm{~d}=1.08)$. No significant improvement in mental and behavioral functioning scores on the YOQ after TF-CBT participation was found in either $\mathrm{C} 7$ or $\mathrm{C} 4-6$ (see Table 4 ). The $\chi 2$ tests results yielded no significant different outcome on measures of justice system involvement between TF-CBT services groups at each of the four post-TF-CBT CY Qtrs.

Table 4: Change in Trauma Symptoms and Mental and Behavioral Functioning within TF-CBT Services Groups

\begin{tabular}{|c|c|c|c|c|c|c|c|c|}
\hline \multirow[t]{2}{*}{ Measures } & \multicolumn{6}{|c|}{ Paired t-test } & \multirow{2}{*}{$\begin{array}{c}\text { Pre-TF-CBT } \\
M(S D) \\
n\end{array}$} & \multirow{2}{*}{$\begin{array}{c}\text { Post-TF-CBT } \\
M(S D) \\
n\end{array}$} \\
\hline & & $M(S D) 95 \% C I$ & $t$ & $d f$ & $p$ & $\begin{array}{c}\text { Cohen's } \\
d\end{array}$ & & \\
\hline $\begin{array}{l}\text { Trauma Symptoms } \\
\text { PTSD RI-19 }\end{array}$ & $\mathrm{C} 7$ & $17.67(16.39) 7.25,28.08$ & $3.73 * *$ & 11 & .003 & 1.08 & $\begin{array}{c}41.42(12.63) \\
12\end{array}$ & $\begin{array}{l}23.75(12.50) \\
12\end{array}$ \\
\hline $\begin{array}{c}\text { Overall Functioning } \\
\text { YOQ }\end{array}$ & $\mathrm{C} 7$ & $15.25(22.79)-3.80,34.30$ & 1.89 & 7 & .100 & 0.67 & $\begin{array}{l}46.92(13.75) \\
12\end{array}$ & $\begin{array}{l}34.50(15.11) \\
8\end{array}$ \\
\hline & C4-6 & $19.30(32.15)-3.70,42.30$ & 1.90 & 9 & .093 & 0.60 & $\begin{array}{c}44.69(19.43) \\
13\end{array}$ & $\begin{array}{l}26.90(22.89) \\
10\end{array}$ \\
\hline
\end{tabular}

Note. TF-CBT = Trauma-Focused Cognitive Behavioral Therapy; PTSD RI = Post Traumatic Stress Disorder Reaction Index; YOQ = Youth Outcomes Questionnaire; C7 = sequentially completed TF-CBT without in vivo; C4-6 $=$ nonsequentially completed 4 to 6 components including trauma narration $\&$ processing. $* *$ p $<.01$.

\section{Discussion}

This study reconfirms that TF-CBT (even without in vivo) results in trauma symptom reduction. However, in order to maximize the benefits of TF-CBT for youth under probation, it is important to tackle the apparent distrust by the youth (of parent/caregiver, therapist, POs and the situation); and, recognize the need to fully prepare therapists in working with justice involved youth within the context of the justice system — both of which are crucial to improving the quality and fidelity of TF-CBT and program effectiveness for the youth under 
probation. The author draws important lessons from SC County's TF-CBT project implementation.

The current study's findings of significant reduction in trauma symptoms on the PTSD RI-19 in C7 (TF-CBT without in vivo, $\mathrm{n}=12$ ) is consistent with earlier meta-analytic or empirical studies on effectiveness of TF-CBT that have reported generally large effect sizes for TF-CBT on trauma symptom reduction [27, 41, 42, 43, 44]. However, the findings of no improvement in mental and behavioral functioning on the YOQ before and after TF-CBT participation was manifest on the last day of TF-CBT treatment session; and, no impact of TFCBT on arrests at first, second, third and fourth CY Qtr after TF-CBT participation, are not consistent with past studies on TF-CBT effectiveness. Prior studies have reported no greater than a medium effect size on behavioral functioning [27], and an earlier TF-CBT effectiveness study in a community setting, where the effect of TF-CBT over time (i.e., up to a year from the beginning of TF-CBT treatment implementation; and 10 sessions on average) was found to be the least stable on externalizing behavioral problems [45]. Perhaps, the 17-day average interval between txS (in C7) which is way beyond the recommended weekly sessions may have affected skills-building and continuity of youth and family/caregiver's supervised learning. This time interval does not allow for continuity of skills to "take hold" and likely contributed to poorer outcomes and potentially to poorer retention. It is also possible that the exclusion of in vivo mastery had affected the outcome - although in vivo is an optional component when clinically indicated [24, 22], not all the anecdotal reasons cited by therapists for in vivo exclusion in the current study were convincing. In a RCT study to compare TF-CBT and client-centered therapy (CCT), families experiencing ongoing exposure to intimate partner violence (IPV), which is similar to the current study's population were provided in vivo component that focused not on mastery of reminders of past IPV, but on helping the youth develop the ability to distinguish between real danger and generalized fears [46, 47].

Overall, despite the TF-CBT project's readiness and responsiveness that enabled implementation, the unaddressed barriers could very well be due to youth low disclosure and development of trust and therapist's skills. These barriers are reflected in the youth's nonresponse, eligible youth declining participation, MHD returning youth to JPD due to ineligibility, and youth reported as not completing TF-CBT. This study finds the significant BGs difference (especially between C7 compared to C4-6 and/or C1-4) in the youth's trauma events experienced, in parental involvement, and engagement suggesting that multiply traumatized youth and their families would have and present more difficulties in completing TF-CBT.

The author calls attention to important lessons from studying SC County's TF-CBT project implementation. First of all, given that creating an environment where a relationship of trust between therapist and client is established is paramount, it is possible that the MHD was viewed by the youth as part of the police system which they instinctively do not trust - the importance of trust in the police (law enforcement) by juveniles/adolescents has been repeatedly emphasized [48] and research has even shown that compared to adults, juveniles tend to profess more hostile attitude against the police, and even more so if they reside in metropolitan areas [49]. Apparently, the trainings have not sufficiently 
prepared the therapists in building trust and caring connection (empathy) with the youth and their caregiver(s), handling ethical conflicts within the context of the justice system, and skillfully assessing trauma and developing treatment plans - it is the ethical responsibility of therapists to inform clients of the limits of confidentiality in therapy [50] and seek confidential consultation from experts and experienced colleagues on ethical conflicts experienced by therapists in a correctional environment $[51,52,53]$. It is a serious oversight to not have recognized the need to fully prepare and support therapists through trustbuilding trainings and consultations to effectively work with justice system involved youth with a background of significant trauma events and coming from a dysfunctional environment (home or neighborhood).

Therapists should be prepared in trauma assessment anticipating the fear or distrust and the need to protect oneself from the unfamiliar situation (prior to contact, during assessment and treatment sessions) by multiply traumatized justice involved youth. The preparations could include trainings (a) in trustbuilding and empathy (b) in providing assistance to low disclosing youth and their caregiver early on during ATCP and in completing self-administered tools (such as the PTSD RI and YOQ), and (c) on when and how a therapist would be suitable to play the parent role to provide TF-CBT and in engaging parents or caregivers - in a study involving a similar population, it has been shown that therapists who had training in how to assess readiness and engage foster parents prior to TF-CBT had more of the youth completing TF-CBT [25]. Therapists could avail of expert consultations on creative ways to provide in vivo if appropriate and systematically addressing challenges to fidelity of TF-CBT. These trainings could potentially reduce the reluctance to disclose severity of need as well as the therapist-youth/family connection that impact the outcome of therapy.

Second, a clinical quality peer review (CQR) staff/team could be designated to support therapists starting from the ATCP sessions, in improving the quality and fidelity of TF-CBT for multiply traumatized youth. An outcome reporting protocol that includes a clear definition of levels of participation, services or completion would be useful for CQR - as such gives an indication of the fidelity of TF-CBT and guidance for follow-up case planning and management. In addition, therapists could assess by the third session the youth's and the caregiver's satisfaction with services (considering that $48.3 \%$ in $\mathrm{C} 1-4$ have dropped out by the fourth session) and addressing issues, such as caregiver limitations that impact youth participation that could reduce withdrawal from therapy. In other words, including a standard clinical quality review and management team would have benefitted this project's implementation.

Third, on the author's side, because the IRB study consent was limited to youth-related data only, a very systematic data collection of information on parents and family could not be done. Information on parents and family could be routinely collected since this data collection may be pertinent to explaining the noninvolvement of parent(s) and family or guardian and understanding barriers to maximizing the conjoint parent-child session.

Fourth, with clear guidance, skillful and experienced therapists should be able to offer TF-CBT and make it easy for youth under probation to avail of the therapy - given that the youth's overall low disclosure as a response to the stigma attached to mental illness and involvement with the legal justice system is 
well known [54] and the extensive literature and research studies that have associated delinquent behaviors and justice involvement with significant youth trauma events which could manifest as violent or aggressive behavior [55, 56, 10 , 57]. Recognizing that it is critical for youth under probation to be assessed for trauma, and their suitable caregiver be engaged by therapists, eligibility requirements could be waived (with clear justifications and supporting documentation) so the youth do not miss the opportunity for TF-CBT.

Fifth, future implementations should consider tracking and systematically collecting data on behaviors that are incompatible with those that would warrant arrests (e.g., youth's attendance in supervised social-educational programs that may be school, community or faith-based) to show the impact of TF-CBT on behavioral functioning - as arrests and incarceration data have been viewed as more indicative of the official response to criminal behavior [58], and considering that in the current study, arrests might not have been precisely captured due to the fact that behaviors that warrant arrests must be reported by someone and/or seen, caught and recorded by proper authorities.

And Lastly, a coherent communications protocol between and among POs, therapists, youth, and caregivers for introduction of TF-CBT, role clarifications, expectations and other opportunities for the youth could result in greater interest, reduce nonresponse, build trust, and avoid conflicts of schedules with other programs. The need for a coherent communications protocol should not have been overlooked.

\section{Conclusion}

Many have strongly argued for better and cost-effective alternatives to youth incarcerations in the USA. The literature reviews include a vast number of studies (a) that have captured the evidence for the negative impact of incarceration on juvenile offenders' health and development [59, 60, 61, 62, 63] and savings from and cost-effectiveness of community-based programs compared to imprisonment $[61,63]$ and (b) that provide support for Evidence-Based Therapies (EBTs) - when properly implemented with fidelity, as a better choice than incarceration $[60,63]$. The reduction in trauma symptoms in multiply traumatized youth under probation would certainly help prepare these youth for follow-up programs that may then focus on behavioral functioning. To improve techniques and processes, it is critical that the outcomes and lessons from implementations of EBTs (such as TF-CBT) in community or outpatient setting for youth under probation and similar populations are disseminated.

\section{Acknowledgment}

The TF-CBT collaborative project was funded by the U.S. Bureau of Justice Assistance Justice and Mental Health Collaborative Project (JMHCP) 2011 Grant to the Santa Clara County Superior Court. The members of the JMHCP TF-CBT Committee were: Judge Patrick Tondreau, TBowles, KDelima, \& CMoran with Superior Court; KAvila, LGarnette, JHowe, JSanchez, \& LSmith 
with the JPD; YAscue, BCopley, AKong, SMonte, BSalada, STerao, \& DWiley with the MHD; MEPangilinan with Research and Evaluation; the unidentified youth and their families who participated in the program; YAscue, BSalada, KAvila, HNguyen, APham, AKong, \& PEspejo for help with data collection and retrieval; EBautista for data entry; F\&C TF-CBT Clinical Team; Dr. Anthony Mannarino for TF-CBT training and consultancies; Ms. CKimmelman-DeVries \& Dr. Marrow for program technical assistance; and the UCSF Research Group: Drs. Martha Shumway, SDarrow, LFields, JParmenter, DYoung, HZhang, CValdez, CChia-Ying \& AMeltzer for helpful comments on the manuscript. Special acknowledgements to Yuki Ascue for invaluable assistance and suggestions.

\section{Disclaimer}

The research reported here does not reflect the views of the Santa Clara County Behavioral Health Services Department, Juvenile Probation Department and Superior Court of Santa Clara County.

\section{References}

1. Zelechoski, A. (2016). Trauma, adverse experience, and offending. In K. Heilbrun (Ed.), APA handbook of psychology and juvenile justice (pp. 325-342). http://dx.doi.org/10.1037/14643-015

2. Abram, K., Teplin, L., Charles, D., Longworth, S., McClelland, G., \& Dulcan, M. (2004). Posttraumatic stress disorder and trauma in youth in juvenile detention. Archives of General Psychiatry, 61, 403-410. http://dx.doi.org/10.1001/archpsyc.61.4.403

3. Abram, K., Washburn, J., Teplin, L., Emanuel, K., Romero, E., \& McClelland, G. (2007). Posttraumatic stress disorder and psychiatric comorbidity among detained youths. Psychiatric Services, 58(10), 1311-1316. doi:10.1176/appi.ps.58.10.1311

4. Maschi, T., Bradley, C., \& Morgen, K. (2008). Unraveling the link between trauma and delinquency. Youth Violence and Juvenile Justice, 6, 136-157.

http://dx.doi.org/10.1177/1541204007305527

5. Bender, K. (2010). Why do some maltreated youth become juvenile offenders? A call for further investigation and adaptation of youth services. Children and Youth Services Review, 32, 466-473. http://dx.doi.org/10.1016/j.childyouth.2009.10.022

6. Wilson, H., Stover, C., \& Berkowitz, S. (2009). Research review: The relationship between childhood violence exposure and juvenile antisocial behavior: a meta-analytic review. The Journal of Child Psychology and Psychiatry, 50(7), 769-779. doi:10.1111/j.1469-7610.2008.01974.x

7. Ford, J., Elhai, J., Connor, D., \& Frueh, B. (2010). Poly-victimization and risk of posttraumatic, depressive, and substance use disorders and involvement in delinquency in a national sample of adolescents. Journal of Adolescent Health, 46(6), 545-552.

8. Ford, J. (2012). Posttraumatic stress disorder among youth involved in juvenile justice. In E.L. Grigorenko (Ed.), Handbook of juvenile forensic psychology and psychiatry (pp. 485-501). doi:10.1007/978-1-4614-0905-2_31

9. Heilbrun, K., \& Locklair, B. (2016). Forensic assessment of juveniles. In K. Heilbrun (Ed.), APA handbook of psychology and juvenile justice (pp. 345-363). http://dx.doi.org/10.1037/14643-016

10. Feierman, J. \& Ford, J. (2016). Trauma informed juvenile justice systems and approaches. In K. Heilbrun (Ed.), APA handbook of psychology and juvenile justice (pp. 545-573). http://dx.doi.org/10.1037/14643-025

11. Ford, J., Chapman, J., Mack, M., \& Pearson, G. (2006). Pathway from traumatic child victimization to delinquency: Implications for juvenile and permanency court proceedings and decisions. Juvenile and Family Court Journal, 57, 13-26. http://dx.doi.org/10.1111.j.17556988.206.tb00111.x 
12. Norman, S., Elbogen, E., \& Schnurr, P. (Updated Feb 2016). Research findings on PTSD and violence. Retrieved from http://www.ptsd.va.gov/professional/cooccurring/research_on_ptsd_and_violence.asp

13. Allwood, M., Bell, D., \& Horan, J. (2011). Posttrauma numbing of fear, detachment, and arousal predict delinquent behaviors in early adolescence. Journal of Clinical Child \& Adolescent Psychology, 40, 659-667. doi:10.1080/15374416.2011.597081

14. Chassin, L., Mansion, A., Nichter, B. \& Pandika, D. (2016). Substance use and substance use disorders as risk factors for juvenile offending. In K. Heilbrun (Ed.), APA handbook of psychology and juvenile justice (pp. 277-305). http://dx.doi.org/10.1037/14643-013

15. Dierkhising, C., Ko, S., Woods-Jaeger, B., Briggs, E., Lee, R., \& Pynoos, R. (2013). Trauma histories among justice-involved youth: findings from the national child traumatic stress network. European Journal of Psychotruamatology, 4: 20274 - http://dx.doi.org/10.3402/ejpt.v4i0.20274

16. Ford, J., Chapman, J., Hawke, J., \& Albert, D. (2007). Trauma among youth in the juvenile justice system: Critical issues and new directions (Research and Program Brief). Delmar, NY: National Center for Mental Health and Juvenile Justice. www.ncmhjj.com

17. Kerig, P., Ward, R., Vanderzee, K., \& Arnzen Moedell, M. (2009). Posttraumatic stress as a mediator of the relationship between trauma and mental health problems among juvenile delinquents. Journal of Youth and Adolescence, 38, 1214-1225. http://dx.doi.org/10.1007/s10964008-9332-5

18. Kerig, P., Bennett, D., Thompson, M., \& Becker, S. (2012). "Nothing really matters": Emotional numbing as a link between trauma exposure and callousness in delinquent youth. Journal of Traumatic Stress, 25, 272-279. http://dx.doi.org/10.1002/jts.21700

19. King, D., Abram, K., Romero, E., Washburn, J., Welty, L., \& Teplin, L. (2011). Childhood maltreatment and psychiatric disorders among detained youths. Psychiatric Services, 62, 14301438. http://dx.doi.org/10.1176/appi.ps.004412010

20. Mallett, C., Stoddard Dare, P., \& Seck, M. (2009). Predicting juvenile delinquency: The nexus of childhood maltreatment, depression and bipolar disorder. Criminal Behavior and Mental Health, 19, 235-246. http://dx.doi.org/10.1002/cbm.737

21. Rosenberg, H., Vance, J., \& Rosenberg, S., Wolford, G., Ashley, S., \& Howard, M. (2014). Trauma exposure, psychiatric disorders, and resiliency in juvenile-justice-involved youth. Psychological Trauma: Theory, Research, Practice, and Policy, 6, 430-437. http://dx.doi.org/10.1037/a0033199

22. Cohen, J. Mannarino, A., \& Deblinger, E. (2017). Treating trauma and traumatic grief in children and adolescents. New York, NY: The Guilford Press.

23. Cary, C \& McMillen, C. (2012). The data behind dissemination: A systematic review of traumafocused cognitive behavioral therapy for use with children and youth, Children and Youth Services Review, 34, 748-757. doi:10.1016/j.childyouth.2012.01.003

24. Cohen, J. Mannarino, A., \& Deblinger, E. (2006). Treating trauma and traumatic grief in children and adolescents. New York, NY: The Guilford Press.

25. Dorsey, S., Pullmann, M., Berliner, L., Koschmann, E., McKay, M. \& Deblinger, E. (2014). Engaging foster parents in treatment: A randomized trial of supplementing Trauma-focused Cognitive Behavioral Therapy with evidence-based engagement strategies. Child Abuse \& Neglect, 38, 1508-1520. http://dx.doi.org/10.1016/j.chiabu.2014.03.020

26. Cohen, J.A., Mannarino, A. P., Janlowski, K., Rosenberg, S., \& Wolford, G.L. (2016). A randomized implementation study of TF-CBT for adjudicated teens in residential treatment facilities. Child Maltreatment, 21, 156-167. doi:10.1177/1077559515624775

27. Arellano de, M., Lyman, D., Jobe-Shields, L., George, P., Dougherty, R., Daniels, A., Ghose, S., Huang, L., \& Delphin-Rittmon, M (2014). Trauma-focused cognitive behavioral therapy: Assessing the evidence. Psychiatric Services, 65, 591-602. doi:101176/appi.ps.201300255

28. Osher, F. (2012a, March). Implementing evidence-based practices. Orientation and Technical Assistance Events for FY 2011 JMHCP. Plenary session conducted at the Council of State Governments Justice Center, Washington D.C.

29. Osher, F. (2012b, March). Targeting the right people for the right intervention. Orientation and Technical Assistance Events for FY 2011 JMHCP. Plenary session conducted at the Council of State Governments Justice Center, Washington D.C.

30. Santa Clara County Superior Court (2011). Justice and Mental Health Collaborative Project Proposal Submitted to the Bureau of Justice Assistance. Unpublished.

31. Santa Clara County Superior Court (2012-2015). Santa Clara County Superior Court Reports to Bureau of Justice Assistance: 2012-2015. Retrieved from https://www.bjaperformancetools.org/

32. Pynoos, R. \& Steinberg, A. (2012). University of California Post Traumatic Stress Disorder Reaction Index (UCLA PTSD-RI) Version 2012. Unpublished. 
33. Burlingame, G., Wells, M., Lambert, M., \& Reisinger, C. (1998 \& 2002). Youth Outcome Questionnaire (Y-OQ $\left.{ }^{\circledR}-30.2\right)$. American Professional Credentialing Services.

34. Attkisson, C. \& Larsen, D. (2009). Client Satisfaction Questionnaire. www.CSQscales.com

35. Santa Clara County Social Services Agency (January 1, 2011). Quarterly Statistical Data of Public Assistance Families in the County of Santa Clara. Retrieved from https://www.sccgov.org/sites/ssa/debs/stats/Documents/Quarterly-Stat-2011_01.pdf

36. Steinberg, A., Brymer, M., Decker, K., \& Pynoos, R. (2004). The University of California, Los Angeles Post Traumatic Stress Disorder Reaction Index. Current Psychiatry Reports, 6(2), 96100 .

37. Steinberg, A., Brymer, M., Kim, S., Briggs, E., Ippen, C., Ostrowski, S., Gully, K., \& Pynoos, R. (2013). Psychometric properties of the UCLA PTSD Reaction Index: Part I. Journal of Traumatic Stress, 26:1- 9.

38. American Psychiatric Association (2013). Diagnostic and statistical manual of mental disorders ( $5^{\text {th }}$ ed.). Arlington, VA: American Psychiatric Publishing.

39. Burlingame, G., Dunn, T., Hill, M., Cox, J., Wells, M.G., Lambert, M., \& Brown, G. (2004). Administration and Scoring Manual for the $Y-O Q^{T M}$-30.2. www.OQMeasures.com

40. Attkisson, C. \& Greenfield, T. (2004). The UCSF Client Satisfaction Scales: I. The Client Satisfaction Questionnaire-8. In M.E. Maruish (Ed.), The use of psychological testing for treatment planning and outcomes assessment ( $3^{\text {rd }}$ Ed) (pp. 799-811). Vol 3. Mahwah, NJ: Lawrence Erlbaum Associates.

41. Murry, L., Skavenski, S., Kane, J., Mayeya, J., Dorsy, S., Cohen, J., Michalopoulos, L., Imasiku, M. \& Bolton, P (2015). Effectiveness of trauma-focused behavioral therapy among traumaaffected children in Lusaka, Zambia: A randomized clinical trial. Journal of American Medical Association Pediatrics, 169, 761-769. doi:10.1001/jamapediatrics.2015.0580

42. O'Donnell, K., Dorsey, S., Gong, W., Ostermann, J., Whetten, R., Cohen, J., Itemba, D., Manongi, R. \& Whetten, K (2014). Treating maladaptive grief and post-traumatic stress symptoms in orphaned children in Tanzania: group-based trauma-focused cognitive-behavioral therapy. Journal of Traumatic Stress, 27, 664-671. Abstract retrieved from http://psychnet.apa.org

43. Sachser, C., Keller, F. \& Goldbeck, L. (2016). Complex ptsd as proposed for ICD-11: Validation of a new disorder in children and adolescents and their response to trauma-focused cognitive behavioral therapy. Journal of Psychology and Psychiatry, No pagination Specified. Abstract retrieved from http://psychnet.apa.org

44. Sanders, B. \& Hanson, R. (2013, September). Can RCT treatment effects be achieved in community practice of trauma treatment? Paper presented at the Thirteenth ISPCAN European Regional Conference on Child Abuse and Neglect, International Society of Child Abuse and Neglect, Dublin, Ireland. Abstract retrieved from http://psychnet.apa.org

45. Webb, C., Hayes, A., Grasso, D., Laurenceau, JP., \& Deblinger, E. (2014). Trauma-focused cognitive behavioral therapy for youth: Effectiveness in a community setting. Psychological Trauma: Theory, Research, Practice, and Policy, 6, 555-562. http://dx.doi.org/10.1037/a0037364

46. Cohen, J., Mannarino, A., \& Iyengar, S. (2011). Community treatment of posttraumatic stress disorder for children exposed to intimate partner violence. Archives of Pediatrics 83 Adolescent Medicine, 165(1), 16-21.

47. Cohen, J., Mannarino, A., \& Murray, L. (2011). Trauma-focused CBT for youth who experience ongoing traumas. Child Abuse and Neglect, 35, 637-646. DOI:10.1016/j.chiabu.2011.05.002

48. Tyler, T. (2015). Why trust matters with juveniles. American Journal of Orthopsychiatry, 85(6), 93-99.

49. Hurst, Y. (2007). Juvenile attitudes toward the police. Criminal Justice Review, 32(2), 121-141.

50. Appelbaum, P. (2002). Privacy in psychiatric treatment: Threats and responses. American Journal of Psychiatry, 159, 1809-1818.

51. Bonner, R., \& Vandecreek, L. (2006). Ethical decision making for correctional mental health providers. Criminal Justice and Behavior, 33, 542-564.

52. Bruggen, Eytan, Gravier, \& Elger (2013). Medical and legal professionals' attitudes towards confidentiality and disclosure of clinical information in forensic settings: A survey using case vignettes. Medicine, Science, and the Law, 53, 132-148. doi:10.1258/msl.2012.012045

53. Wangmo, T., Handtke, V., \& Elger, B. (2014). Disclosure of past crimes: An analysis of mental health professionals' attitudes towards breaching confidentiality. Journal of Bioethical Inquiry, $11,347-358$.

54. Louden, J., Manchak, S., Ricks, E., \& Kennealy, P. (2018). The role of stigma toward mental illness in probation officers' perceptions of risk and case management decisions. Criminal Justice and Behavior, 45, 573-588. doi:10.1177/00093854818756148 
55. Baer, J. \& Maschi, T. (2003). Random acts of delinquency: Trauma and self-destructiveness in juvenile offenders. Child and Adolescent Social Work Journal, 20, 85-98.

56. DeLisi, M., Drury, A., Kosloski, A., Caudill, J., Conis, P., Anderson, C., Vaugn, M. \& Beaver, K. (2010). The cycle of violence behind bars: Traumatization and institutional misconduct among juvenile delinquents in confinement. Youth Violence and Juvenile Justice, 8, 107-121. doi: $10.1177 / 1541204009349399$

57. Krischer, M. \& Sevecke, K. (2008). Early traumatization and psychopathy in female and male juvenile offenders. International Journal of Law and Psychiatry, 31, 253-262. doi:10.1016/j.ijlp.2008.04.008

58. Elliott, D. (1995). Lies, damn lies and arrest statistics. The American Society of Criminology Meetings. The Sutherland Award Presentation. Boston, Massachusetts. Retrieved from https://www.colorado.edu/UCB/Research/cspv/publications/papers/CSPV-015.pdf

59. Henggeler, S. (2016). Community-based interventions for juvenile offenders In K. Heilbrun (Ed.), APA handbook of psychology and juvenile justice (pp. 575-595). http://dx.doi.org/10.1037/14643026

60. Mendel, R. (2011). No place for kids: The case for reducing juvenile incarceration. Baltimore, MD: Annie E. Casey Foundation. Retrieved from https://files.eric.ed.gov/fulltext/ED527944.pdf

61. Bryer, S. \& Levin, M. (2013). The comeback states: Reducing youth incarceration in the United States. Washington, DC: National Juvenile Justice Network and the Center for Effective Justice, Texas Public Policy Foundation.

62. Lambie, I., \& Randell, I. (2013). The impact of incarceration on juvenile offenders. Clinical Psychology Review, 33, 448-459. http://dx.doi.org/10.1016/j.cpr.2013.01.007

63. Petteruti, A., Walsh, N., \& Velazquez, T. (2009). The costs of confinement: Why good juvenile justice policies make good fiscal sense. Washington, DC: Justice Policy Institute. http://www.justicepolicy.org 
Appendix A: PTSD RI-19 and YOQ Subscales Reliability for All Participants and by TF-CBT Youth Group

\begin{tabular}{|c|c|c|c|c|c|c|c|c|c|c|c|c|c|}
\hline \multirow[b]{3}{*}{$\begin{array}{l}\text { Clinical } \\
\text { Characteristics }\end{array}$} & \multicolumn{9}{|c|}{ Pre-TF-CBT } & \multicolumn{4}{|c|}{ Post-TF-CBT } \\
\hline & \multicolumn{2}{|l|}{ All } & \multicolumn{2}{|c|}{$\mathrm{C} 7$} & \multicolumn{2}{|c|}{ C4-6 } & \multicolumn{2}{|c|}{ C1-4 } & \multirow[t]{2}{*}{$F$ score } & \multicolumn{2}{|l|}{$\mathrm{C} 7$} & \multicolumn{2}{|c|}{ C4-6 } \\
\hline & $\begin{array}{c}M \\
(S D)\end{array}$ & $a$ & $\begin{array}{c}M \\
(S D) \\
\text { range }\end{array}$ & $a$ & $\begin{array}{c}M \\
(S D) \\
\text { range }\end{array}$ & $a$ & $\begin{array}{c}M \\
(S D) \\
\text { range }\end{array}$ & $a$ & & $\begin{array}{c}M \\
(S D) \\
\text { range }\end{array}$ & $a$ & $\begin{array}{c}M \\
(S D) \\
\text { range }\end{array}$ & $a$ \\
\hline $\begin{array}{l}\text { Trauma Symptoms } \\
\text { on the PTSD RI-19 }\end{array}$ & $n=51-$ & & $n=1$ & & $n=1$ & -13 & $n=28$ & & $n=51-54$ & $n=1$ & & $n=$ & \\
\hline Intrusion & $\begin{array}{c}9.39 \\
(4.93)\end{array}$ & .73 & $\begin{array}{c}10.83 \\
(5.62) \\
3-20\end{array}$ & .82 & $\begin{array}{c}10.00 \\
(5.24) \\
0-17\end{array}$ & .76 & $\begin{array}{c}8.52 \\
(4.46) \\
0-17\end{array}$ & .66 & 1.07 & $\begin{array}{c}4.92 \\
(3.15) \\
2-12\end{array}$ & .63 & $\begin{array}{c}4.90 \\
(4.04) \\
0-13\end{array}$ & .85 \\
\hline Avoidance & $\begin{array}{c}4.04 \\
(2.24)\end{array}$ & .48 & $\begin{array}{c}3.17 \\
(2.29) \\
0-8\end{array}$ & .41 & $\begin{array}{c}4.31 \\
(1.93) \\
0-8\end{array}$ & .06 & $\begin{array}{c}4.28 \\
(2.33) \\
0-8\end{array}$ & .59 & 1.17 & $\begin{array}{c}2.75 \\
(1.55) \\
1-6\end{array}$ & .00 & $\begin{array}{c}2.70 \\
(2.63) \\
0-8\end{array}$ & .64 \\
\hline Negative Cognitions & $\begin{array}{l}11.44 \\
(5.16)\end{array}$ & .65 & $\begin{array}{c}13.25 \\
(5.40) \\
4-24\end{array}$ & .63 & $\begin{array}{c}12.73 \\
(4.13) \\
5-18\end{array}$ & .36 & $\begin{array}{c}10.21 \\
(5.23) \\
0-22\end{array}$ & .69 & 1.98 & $\begin{array}{c}7.42 \\
(5.62) \\
2-22\end{array}$ & .84 & $\begin{array}{c}5.60 \\
(5.08) \\
0-15\end{array}$ & .81 \\
\hline Arousal / Reactivity & $\begin{array}{l}12.68 \\
(3.77)\end{array}$ & .47 & $\begin{array}{c}14.17 \\
(3.27) \\
8-19\end{array}$ & .38 & $\begin{array}{c}12.69 \\
(3.50) \\
8-20\end{array}$ & .47 & $\begin{array}{c}12.04 \\
(4.01) \\
1-18\end{array}$ & .49 & 1.36 & $\begin{array}{c}8.67 \\
(4.34) \\
2-16\end{array}$ & .73 & $\begin{array}{c}8.00 \\
(4.35) \\
0-15\end{array}$ & .65 \\
\hline $\begin{array}{l}\text { Functioning on the } \\
\text { YOQ }\end{array}$ & $n=52-53$ & & $n=12$ & & $n=13$ & & $n=27-29$ & & & $n=8$ & & $n=10$ & \\
\hline Somatic & $\begin{array}{c}5.11 \\
(16.93)\end{array}$ & .63 & $\begin{array}{c}5.83 \\
(2.98) \\
3-11\end{array}$ & .47 & $\begin{array}{c}5.54 \\
(6.94) \\
0-9\end{array}$ & .62 & $\begin{array}{c}4.61 \\
(11.80) \\
0-12\end{array}$ & .68 & 0.79 & $\begin{array}{c}4.50 \\
(1.93) \\
2-8\end{array}$ & -.17 & $\begin{array}{c}3.00 \\
(3.62) \\
0-11\end{array}$ & .85 \\
\hline Social Isolation & $\begin{array}{c}1.23 \\
(1.53)\end{array}$ & .11 & $\begin{array}{c}1.42 \\
(1.44) \\
0-4\end{array}$ & -.70 & $\begin{array}{c}0.92 \\
(1.74) \\
0-4\end{array}$ & .06 & $\begin{array}{c}1.30 \\
(2.83) \\
0-5\end{array}$ & .37 & 0.37 & $\begin{array}{c}1.25 \\
(1.39) \\
0-4\end{array}$ & .11 & $\begin{array}{c}1.50 \\
(2.72) \\
0-7\end{array}$ & .94 \\
\hline Aggression & $\begin{array}{l}3.28 \\
(2.82)\end{array}$ & .64 & $\begin{array}{c}3.08 \\
(2.78) \\
0-9\end{array}$ & .79 & $\begin{array}{c}3.23 \\
(8.86) \\
0-10\end{array}$ & .78 & $\begin{array}{c}3.39 \\
(8.25) \\
0-10\end{array}$ & .55 & 0.05 & $\begin{array}{c}1.75 \\
(2.44) \\
0-7\end{array}$ & .80 & $\begin{array}{c}1.50 \\
(1.90) \\
0-5\end{array}$ & .53 \\
\hline Conduct Problems & $\begin{array}{c}8.27 \\
(5.01)\end{array}$ & .73 & $\begin{array}{c}8.08 \\
(4.48) \\
0-14\end{array}$ & .60 & $\begin{array}{c}8.15 \\
(5.24) \\
0-16\end{array}$ & .80 & $\begin{array}{c}8.41 \\
(5.29) \\
1-17\end{array}$ & .76 & 0.02 & $\begin{array}{c}5.50 \\
(4.44) \\
0-12\end{array}$ & .71 & $\begin{array}{c}4.30 \\
(3.50) \\
0-11\end{array}$ & .77 \\
\hline $\begin{array}{l}\text { Hyperactivity } \\
\text { /Distractibility }\end{array}$ & $\begin{array}{c}6.15 \\
(2.74)\end{array}$ & .40 & $\begin{array}{c}5.67 \\
(2.71) \\
3-12\end{array}$ & .34 & $\begin{array}{c}5.08 \\
(2.87) \\
0-12\end{array}$ & .57 & $\begin{array}{c}6.89 \\
(2.56) \\
0-11\end{array}$ & .26 & 2.27 & $\begin{array}{c}3.88 \\
\\
(2.80) \\
0-9\end{array}$ & .75 & $\begin{array}{c}2.90 \\
(2.51) \\
0-7\end{array}$ & .80 \\
\hline Depression / Anxiety & $\begin{array}{c}9.50 \\
(3.40)\end{array}$ & .52 & $\begin{array}{c}10.25 \\
(3.22) \\
6-16\end{array}$ & .14 & $\begin{array}{c}9.92 \\
(4.94) \\
3-20\end{array}$ & .72 & $\begin{array}{c}8.96 \\
(3.88) \\
2-18\end{array}$ & .50 & 0.52 & $\begin{array}{c}6.75 \\
(3.69) \\
2-12\end{array}$ & .52 & $\begin{array}{c}5.90 \\
(6.19) \\
0-21\end{array}$ & .94 \\
\hline
\end{tabular}

Note. PTSD = Post Traumatic Stress Disorder; YOQ = 30-item Youth Outcomes Questionnaire Version 30.2.

TF-CBT = Trauma-Focused Cognitive Behavioral Therapy; C7 = sequentially completed TF-CBT without in vivo;

C4-6 = nonsequentially completed 4 to 6 components including trauma narration \& processing; C1-4= completed 1 to 4 of any one or a combination of the first four TF-CBT components. 